Изв. АН Эстонии. Хим., 1989, 38, № 4, 274-278

удК $553.982: 547.495 .2: 543.42: 543.54$

Сайма САЛУСТЕ, Евгения БОНДАРЬ, И. БЛЯХИНА

\title{
ВЫДЕЛЕНИЕ ПОЛИЦИКЛИЧЕСКИХ НАФТЕНОВ И РАЗ- ВЕТВЛЕННЫХ АЛКАНОВ ИЗ СМЕСИ ИХ С ЖАЛКАНАМИ МЕТОДОМ КОМПЛЕКСООБРАЗОВАНИЯ С МОЧЕВИНОЙ
}

(49) В органической геохимии полициклические нафтены (стераны и тритерпаны) и метилразветвленные алканы относят к «биологическим меткам» первого порядка, которые при изучении фоссилизированного органического вещества на молекулярном уровне несут важную геохимическую информацию о его биологических предшественниках и превращениях в земной коре. Важная роль отводится стеранам и тритерпанам при проведении генетических корреляций между нефтематеринскими породами и нефтями: методом хромато-масс-спектрометрии с компьютерным обеспечением изучаются и сравниваются их состав и соотношение стереоизомеров в нефти и в экстрагируемой части органического вещества (битумоиде) породы. Қак показали исследования последних лет, под воздействием геотермического градиента (при глубоком погружении) или тепла магматических интрузий горючие сланцы генерируют нефть ['].

Содержание стеранов и тритерпанов в битумоидах горючих сланцев достаточно для их детального исследования методом хромато-массспектрометрии $\left[{ }^{2}\right]$, в нефтях оно значительно ниже, и требуется предварительное концентрирование этих полициклических нафтенов. Этого можно достигнуть выделением $н$-алканов - основных компонентов большинства нефтей, для чего в лабораторной практике широко используется метод комплексообразования с мочевиной [].

Для протекания реакции в направлении образования комплекса включения $\boldsymbol{H}$-алканов в систему гексагональных каналов в кристаллах мочевины необходимо три условия: 1) применение инертного растворителя, 2) добавление активатора, 3) обеспечение низкой температуры процесса. Требуется такое количество мочевины, которого достаточно для выделения $H$-алканов и для насыщения раствора: $m=0,653 n+1,51$, где $m-$ число молей мочевины, $n-$ среднее число атомов углерода в молекуле $н$-алкана [3].

При разделении нейтральной части битумоидов сланцев методом препаративной тонкослойной хроматографии (ТСX) $\left[{ }^{4}\right]$ полициклические нафтены выделяются в смеси с $\mu$-и изоалканами (алкановая ТCXфракция). Для получения сопоставимых результатов методику анализа битумоидов горючих сланцев использовали и при исследовании нефтей [5], в результате чего были получены алкановые ТСХ-фракции, содержащие вместе с нефтяными $н$ - и изоалканами полициклические нафтены. Әти фракции и подвергали комплексообразованию, так как они не содержат ароматических углеводородов, которые могут адсорбиров|аться на поверхности реагентов и снижать эффективность комплексообразования.

\section{Методика эксперимента}

$\mathrm{C}$ помощью модельной смеси н-алканов $\mathrm{C}_{10}, \mathrm{C}_{11}, \mathrm{C}_{13}, \mathrm{C}_{14}, \mathrm{C}_{23}$ (соответственно $21,21,24,26,6 \%$ ) были определены условия комплексообразования:

$\begin{array}{ll}\text { масса пробы }-0,05 \text { г } & \text { объем метанола - 2,0 мл } \\ \text { масса мочевины }-2,0 \text { г } & \text { объем н-пентана }-5,0 \text { мл }\end{array}$ 
Пробу (алкановую ТСХ-фракцию нефти) растворяли в н-пентане при комнатной температуре, добавляли мочевину. Затем полученную смесь при постоянном перемешивании охлаждали до $0^{\circ} \mathrm{C}$, порциями добавляли 2 мл активатора (метанола) и продолжали комплексообразование в течение 3 ч. Образовавшийся комплекс отделяли через стеклянный фильтр, промывали охлажденным $H$-пентаном, а затем разлагали горячей водой $\left(60-80^{\circ} \mathrm{C}\right)$ и отделяли высвободившиеся $н$-алканы. Водную фазу дважды экстрагировали диэтиловым эфиром, экстракты прибавляли к основной порции $н$-алканов, сушили безводным сульфатом натрия, фильтровали и отгоняли диэтиловый эфир. От остатка комплексообразования, в котором содержатся полициклические нафтены, отгоняли н-пентан.

Газохроматографический анализ проводили на приборе «Хром-41»в условиях программирования температуры. Газнноситель - гелий. ИКспектры снимали на спектрофотометре «Specord 75 IR».

\section{Результаты и их обсуждение}

Материальные балансы опытов по комплексообразованию с мочевиной алкановых ТСХ-фракций 27 образцов конденсатов и нефтей БухароХивинской нефтегазоносной области приведены в таблице. н-Алканы, включившиеся в комплекс с мочевиной, и остатки комплексообразования охарактеризованы ГЖХ (рис. 1, 2) и ИК-спектроскопией (рис. 3).

Судя по представленным данным, в случае конденсатов комплексообразование проходит слабо, так как они содержат низкомолекулярные гомологи $н$-алканов, а $н$-алканы до $\mathrm{C}_{12}$ плохо включаются в комплекс с мочевиной. С ростом плотности нефтей (в таблице они расположены в порядке возрастания этого показателя) увеличивается и степень комплексообразования за счет увеличения содержания в них более высокомолекулярных н-алканов.

Рис. 1. Хроматограммы алкановой ТСХ-фракцин нормальной нефти (обр. 9) (a), н-алканов (б) и остатка комплексообразования с мочевиной (в). Цифры у пиков соответствуют чнслу атомов углерода в молекуле $\boldsymbol{H}$-алкана. Изопренонды обозначены индексом $i$. Колонкн: а -49 м $\times 0,25$ мм, OV-101; 6, в - 3,7 м $\times 3$ мм, $4 \%$ E-301 на хроматоне N AW HMDS, $0,125-0,160 \quad$ мм (здесь и на рис. 2).

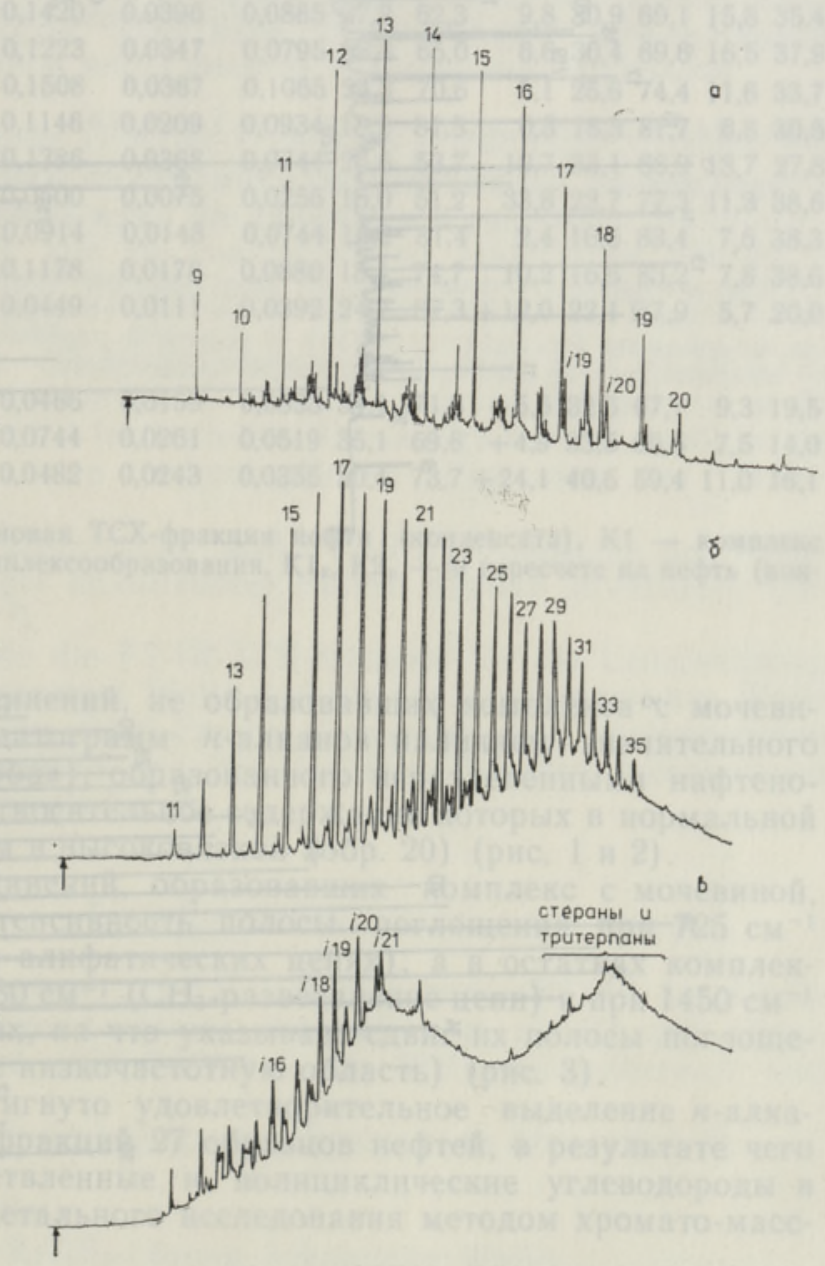



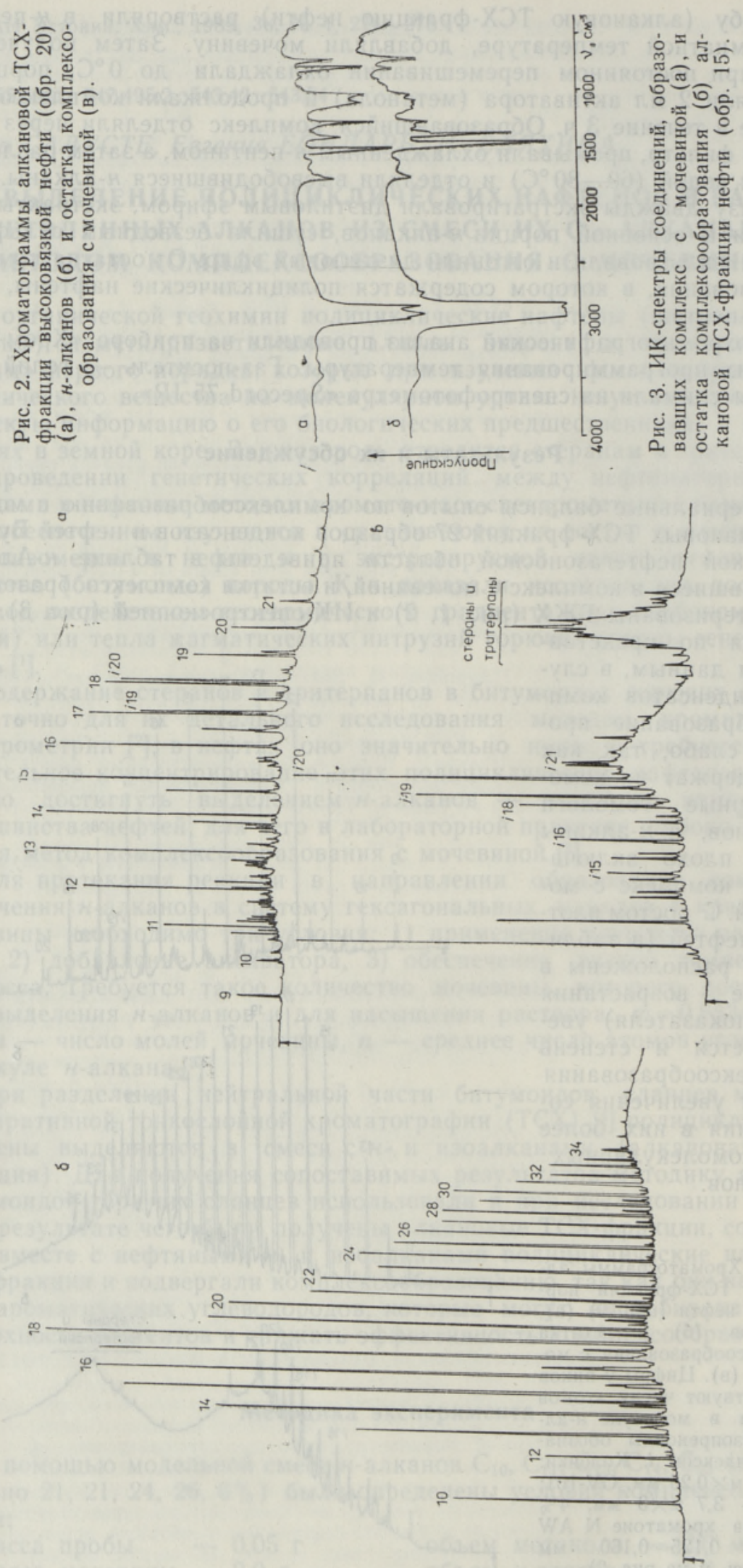


\begin{tabular}{|c|c|c|c|c|c|c|c|c|c|c|c|c|c|}
\hline $\begin{array}{l}\text { 릎 } \\
\text { 일 } \\
\text { \% }\end{array}$ & 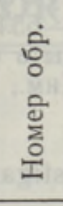 & 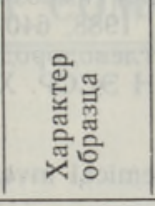 & 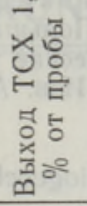 & 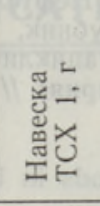 & $\bar{\Sigma}$ & $\stackrel{\check{I}}{\check{I}}$ & 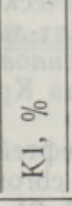 & $\begin{array}{l}\text { i } \\
\text { व }\end{array}$ & 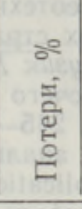 & 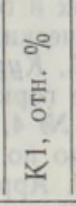 & 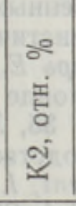 & ¿ & ¿̊ \\
\hline 1 & 2 & конденсат & 100,0 & 1,8852 & 0,0339 & 1,0767 & 1,8 & 57,1 & 41,1 & 3,1 & 96,9 & 3,1 & 96,9 \\
\hline 2 & 1 & $"$ & 100,0 & 1,2234 & 0,1280 & 0,6764 & 10,5 & 55,3 & 34,2 & 15,9 & 84,1 & 15,9 & 84,1 \\
\hline 3 & 31 & $n$ & 77,2 & 0,2585 & 0,0453 & 0,1294 & 17,5 & 50,1 & 32,4 & 25,9 & 74,1 & 20,0 & 57,2 \\
\hline 4 & 3 & " & 68,6 & 0,1926 & 0,0295 & 0,1269 & 15,3 & 65,9 & 18,8 & 18,9 & 81,1 & 13,0 & 55,6 \\
\hline 5 & 5 & нефть & 60,8 & 0,0951 & 0,0225 & 0,0642 & 23,7 & 67,5 & 8,8 & 26,0 & 74,0 & 15,8 & 45,0 \\
\hline 6 & 4 & $"$ & 63,8 & 0,1827 & 0,0590 & 0,1163 & 32,3 & 63,7 & 4,0 & 33,7 & 66,3 & 21,5 & 42,3 \\
\hline 7 & 32 & , & 52,6 & 0,0463 & 0,0148 & 0,0295 & 32,0 & 63,7 & 4,3 & 33,4 & 66,6 & 17,6 & 35,0 \\
\hline 8 & 30 & $"$ & 63,9 & 0,2364 & 0,0820 & 0,1564 & 34,7 & 66,2 & $+0,9$ & 34,4 & 65,6 & 22,0 & 41,9 \\
\hline 9 & 11 & " & 55,3 & 0,1689 & 0,0311 & 0,0852 & 18,4 & 50,4 & 31,2 & 26,7 & 73,3 & 14,8 & 40,5 \\
\hline 10 & 6 & " & 56,6 & 0,1700 & 0,0765 & 0,1212 & 45,0 & $71,3-$ & $+16,3$ & 38,7 & 61,3 & 21,9 & 34,7 \\
\hline 11 & 7 & " & 53,9 & 0,1167 & 0,0328 & 0,0829 & 28,1 & 71,0 & 0,9 & 28,3 & 71,7 & 15,3 & 38,6 \\
\hline 12 & 16 & " & 65,5 & 0,2090 & 0,0636 & 0,1236 & 30,4 & 59,1 & 10,5 & 34,0 & 66,0 & 22,3 & 43,2 \\
\hline 13 & 10 & $"$ & 54,1 & 0,1689 & 0,0556 & 0,1077 & 32,9 & 63,8 & 3,3 & 34,0 & 66,0 & 18,4 & 35,7 \\
\hline 14 & 12 & $"$ & 52,8 & 0,1736 & 0,0412 & 0,1272 & 23,7 & 73,3 & 3,0 & 24,5 & 75,5 & 12,9 & 39,9 \\
\hline 15 & 17 & 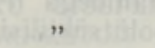 & 51,7 & 0,1652 & 0,0343 & 0,1169 & 20,8 & 70,8 & 8,4 & 22,7 & 77,3 & 11,7 & 40,0 \\
\hline 16 & 18 & $"$ & 51,2 & 0,1420 & 0,0396 & 0,0885 & 27,9 & 62,3 & 9,8 & 30,9 & 69,1 & 15,8 & 35,4 \\
\hline 17 & 8 & , & 54,4 & 0,1223 & 0,0347 & 0,0795 & 28,4 & 65,0 & 6,6 & 30,4 & 69,6 & 16,5 & 37,9 \\
\hline 18 & 29 & " & 45,3 & 0,1508 & 0,0367 & 0,1065 & 24,3 & 70,6 & 5,1 & 25,6 & 74,4 & 11,6 & 33,7 \\
\hline 19 & 14 & " & 37,3 & 0,1146 & 0,0209 & 0,0934 & 18,2 & 81,5 & 0,3 & 18,3 & 81,7 & 6,8 & 30,5 \\
\hline 20 & 25 & & 41,5 & 0,1386 & 0,0368 & 0,0744 & 26,6 & 53,7 & 19,7 & 33,1 & 66,9 & 13,7 & 27,8 \\
\hline 21 & 15 & , & 49,9 & 0,0500 & 0,0075 & 0,0256 & 15,0 & 51,2 & 33,8 & 22,7 & 77,3 & 11,3 & 38,6 \\
\hline 22 & 13 & , & 45,9 & 0,0914 & 0,0148 & 0,0744 & 16,2 & 81,4 & 2,4 & 16,6 & 83,4 & 7,6 & 38,3 \\
\hline 23 & 9 & & 46,4 & 0,1178 & 0,0178 & 0,0880 & 15,1 & 74,7 & 10,2 & 16,8 & 83,2 & 7,8 & 38,6 \\
\hline 24 & 22 & $\begin{array}{c}\text { высоко- } \\
\text { вязкая } \\
\text { нефть }\end{array}$ & 25,7 & 0,0449 & 0,0111 & 0,0392 & 24,7 & $87,3-$ & $+12,0$ & 22,1 & 77,9 & 5,7 & 20,0 \\
\hline 25 & 19 & " & & & & & 34,1 & 71,5 & 5,6 & 32,3 & 67,7 & 93 & 19 \\
\hline 26 & 20 & & 21,5 & 0,0744 & 0,0261 & 0,0519 & 35,1 & 69,8 & $+4,9$ & 33,5 & 66,5 & 7,5 & 14,0 \\
\hline 27 & 21 & & 27,1 & 0,0482 & 0,0243 & 0,0355 & 50,4 & $73,7-$ & $+24,1$ & 40,6 & 59,4 & 11,0 & 16,1 \\
\hline
\end{tabular}

Примечание: ТСХ 1 - алкановая ТСХ-фракция нефти (конденсата), К1 - комплекс включения, К2 - остаток комплексообразования, $\mathrm{K} 1_{\mathrm{H}}, \mathrm{K} 2_{n}-$ в пересчете на нефть (конденсат).

Хроматограммы соединений, не образовавших комплекса с мочевиной, отличаются от хроматограмм $н$-алканов наличием значительного нафтенового фона («горба»), образованного неразделенными нафтеновыми углеводородами, относительное содержание которых в нормальной нефти (обр. 9) выше, чем в высоковязкой (обр. 20) (рис. 1 и 2).

В ИК-спектрах соединений, образовавших комплекс с мочевиной, выше относительная интенсивность полосы поглощения при $725 \mathrm{~cm}^{-1}$ $\left(\mathrm{CH}_{2}\right.$-группы в длинных алифатических цепях), а в остатках комплексообразования - при $1380 \mathrm{~cm}^{-1}\left(\mathrm{CH}_{3}\right.$-разветвление цепи) и при $1450 \mathrm{~cm}^{-1}$ $\left(\mathrm{CH}_{2}\right.$-группы в алициклах, на что указывает сдвиг их полосы поглощения от $1460 \mathrm{~cm}^{-1}$ в более низкочастотную область) (рис. 3).

Таким образом, достигнуто удовлетворительное выделение $\boldsymbol{H}$-алканов из алкановых ТСХ-фракций 27 образцов нефтей, в результате чего сконцентрированы разветвленные и полициклические углеводороды в целях их дальнейшего детального исследования методом хромато-массспектрометрии. 
1. Бондарь Е., Клесмент И. Нефти, образующиеся из сапропелитовых топлив в естественных и геотехнологических условиях // VI Нефтехимический симпозиум социалистических стран. Мат-лы симп., III. Козубник, Польша, 1988, 640-654.

2. Бондарь $E$., Куузик М., Осипов $Г$. Тетра- и пентациклические углеводороды в битумоиде горючего сланца Красава (НР Болгария) // Изв. АН ЭССР. Хим., 19£ร,,

35 , № 4, 245-254.

3. Руководство по анализу нефтей. Л., 1966.

4. Klesment, I. Application of chromatographic methods in biogeochemical investigations // J. Chromatogr., 1974, 91, N 2, 705-713.

5. Бондарь Е. Б., Салусте С. Я., Битюков М. М. Применение методики исследования органического вещества горючих сланцев для анализа нефтей // Горючие сланцы (в печати).

Ннститут химии

Академии наук Эстонской ССР
Поступила в редакцию $2 /$ II 1989

\section{Saima SALUSTE, Jevgenia BONDAR, I. BLJAHHINA}

\section{POLUTSUKLILISTE NAFTEENIDE JA HARGNENUD ALKAANIDE ERALDAMINE NENDE JA $n$-ALKAANIDE SEGUST KARBAMIIDI KOMPLEKSIMOODUSTAMISE MEETODIGA}

Ohukese kihi kromatograafilise meetodiga eraldati 27 naftaproovist alkaanide fraktsioon. Seda rikastati polütsükliliste nafteenide ja hargnenud alkaanidega $n$-alkaanide suhtes karbamiidi kompleksi moodustamisega, et detailselt uurida polütsüklilisi nafteene (steraane ja triterpaane) kromatomassi-spektromeetrilise meetodi abil.

\section{Saima SALUSTE, Eugenia BONDAR, I. BLYAKHINA}

\section{SEPARATION OF POLYCYCLIC NAPHTHENES AND BRANCHED ALKANES FROM $n$-ALKANES BY UREA ADDUCTION}

The satisfactory concentration of polycyclic naphthenes and branched alkanes of 27 oil samples has been obtained due to the separation of $n$-alkanes by urea adduction for the following detailed investigation of polycyclic naphthenes (steranes and triterpanes) by computerized gas chromatography-mass spectrometry. 